\title{
Laurent Dubreuil, De l'attrait à la possession: Maupassant, Artaud, Blanchot
}

\section{Emanuele Kanceff}

\section{(2) OpenEdition}

1 Journals

\section{Edizione digitale}

URL: https://journals.openedition.org/studifrancesi/39752

DOI: 10.4000/studifrancesi.39752

ISSN: 2421-5856

\section{Editore}

Rosenberg \& Sellier

\section{Edizione cartacea}

Data di pubblicazione: 1 décembre 2004

Paginazione: 408

ISSN: 0039-2944

\section{Notizia bibliografica digitale}

Emanuele Kanceff, «Laurent Dubreuil, De l'attrait à la possession: Maupassant, Artaud, Blanchot», Studi Francesi [Online], 143 (XLVIII | II) | 2004, online dal 30 novembre 2015, consultato il 19 mai 2021. URL: http://journals.openedition.org/studifrancesi/39752 ; DOI: https://doi.org/10.4000/studifrancesi. 39752

Questo documento è stato generato automaticamente il 19 mai 2021.

\section{(c) (1)}

Studi Francesi è distribuita con Licenza Creative Commons Attribuzione - Non commerciale - Non opere derivate 4.0 Internazionale. 


\title{
Laurent Dubreuil, De l'attrait à la possession: Maupassant, Artaud, Blanchot
}

\author{
Emanuele Kanceff
}

\section{NOTIZIA}

LAURENT DUBReUIL, De l'attrait à la possession: Maupassant, Artaud, Blanchot, Paris, Hermann éditeurs des Sciences et des Lettres, 2003 («Savoir: Lettres»), pp. VI, 348

1 «Non sono più me stesso. Qualcuno mi possiede, mi attraversa, mi distrugge. Parlo, scrivo e non riconosco la mia voce. Dico cose senza volerlo, non è il mio linguaggio. Mi si spoglia, mi s'inganna, mi si utilizza. Divento un luogo di passaggio per forze immense, mi abituo a subire...».

2 L'interesse di questo libro è puntato sulle esperienze di possessione, che vuole interrogare nei loro rapporti con la letteratura. A tal fine, l'A. ha scelto tre guide, Maupassant, Artaud e Blanchot. Per ragioni di limiti temporali, ci potremo occupare soltanto del secondo.

3 Nei testi scritti da Artaud nel dopoguerra sono sempre presenti possessione, esorcismi, magìa, che formano un fondo permanente, la tela sulla quale si disegnano i suoi cahiers. A differenza di Maupassant e soprattutto di Blanchot, con Artaud la magia e la possessione non sono esperienze come le altre, ma tendono a rendere conto della realtà stessa.

4 L'A. analizza con finezza nei testi quest'atmosfera d'incantesimo e di seduzione che degenera in possessione, contro la quale Artaud pare crearsi un linguaggio nuovo, che l'A. definisce e documenta nei testi. L'evidenza della magia nera e della possessione richiede un gigantesco dispositivo di difesa e di attacco. Ma, incapace di dominare la possessione, Artaud si suicida nella letteratura e con la letteratura: l'opera, trestimone di un insuccesso, rende sublime il passaggio alla letteratura: Artaud sancisce la 
possessione e vuol mostrarne una prova per mezzo della sua opera letteraria, servendosi della sua esistenza per attestare l'avvenimento sofferto della tortura della possessione. 